\title{
Influence of Ca Content on the Structure and Properties of (Co, Ca)O Thin Films Deposited by PLD Technique
}

\author{
L. CienieK* AND S. KaC \\ Faculty of Metals Engineering and Industrial Computer Science, AGH University of Science and Technology \\ 30 Mickiewicza Ave., 30-059 Cracow, Poland \\ In this paper the results of investigations of pure and Ca-doped $\mathrm{CoO}$ thin films deposited by PLD technique \\ are presented. The studies carried out for variable Ca content allowed to establish optimal conditions for good \\ quality oxide films preparation. The microstructure, chemical/phase composition and morphology of obtained \\ thin films were examined by means of diverse techniques (SEM, EDS, XPS and XRD). For estimation of deposited \\ Ca-doped $\mathrm{CoO}$ films quality the nanohardness and scratch tests (adhesion) were performed. Obtained results \\ confirm that using PLD technique it is possible to carry stoichiometric composition of (Co, Ca) O from target \\ to single crystal substrate and allow to conclude that the calcium dopant concentration (chemical composition) \\ influence on the morphology and measured properties of deposited ( $\mathrm{Co}, \mathrm{Ca}) \mathrm{O}$ films.
}

PACS numbers: 81.15.Fg, 81.15.-z, 81.15.Aa, 68.55.-a, 68.60.Bs, 68.37.-d, 68.55.jd

\section{Introduction}

In recent years analysis of pure $\mathrm{CoO}$ and $(\mathrm{Co}, \mathrm{Ca}) \mathrm{O}$ single crystals, have been made to indicate the influence of $\mathrm{Ca}$ content on the structure and properties of ionic oxides [1]. Results of this research allow to conclude that $\mathrm{Ca}$-doped $\mathrm{CoO}$ crystals reveal reversible abrupt decrease of electrical conductivity at high temperature $\left(1000-1400^{\circ} \mathrm{C}\right)$ and low oxygen partial pressure (below $\left.10^{-3} \mathrm{~atm}\right)$. The reason for this phenomenon is the presence of more complex defect structure at high temperatures (4:1 clusters apart from simple cation vacancies). $\mathrm{Co}^{+}$cations are responsible for the conductivity decrease. Their presence decreases the concentration of electron holes that reduce carrier's amount. The very fine spherical phase, observed by transmission electron microscopy only for specified range of oxygen activity, is responsible for abrupt decrease of the conductivity for ( $\mathrm{Co}, \mathrm{Ca}) \mathrm{O}$ oxides. TEM, coupled to EDS analyses, revealed the presence of $\mathrm{Co}_{3} \mathrm{O}_{4}$ precipitates, whose density, shape and size change with the amount of $\mathrm{Ca}$. The electrical properties change is also the consequence of $\mathrm{Co}_{3} \mathrm{O}_{4}$ spinel phase concentration decrease (presence of phase boundaries), as well as the dislocations density [2]. Since reversible transport properties changes are observed for very specified range of oxygen partial pressure and high temperature there is much to be said for ( $\mathrm{Co}, \mathrm{Ca}) \mathrm{O}$ to be the functional material used for gas sensors. Cobalt oxides $(\mathrm{CoO}$ and $\mathrm{Co}_{3} \mathrm{O}_{4}$ ) exhibit many interesting electronic and magnetic properties and are widely used as catalysts [3], pigments for glasses and ceramics, electrochromic materials [4], electrochemical anodes [5], electrochemical capac-

\footnotetext{
* corresponding author; e-mail: cieniek@agh.edu.pl
}

itors for high power devices [6]. Contemporary tendency for miniaturization in materials science [7] extort adaptation of the most recent production techniques, like Pulsed Laser Deposition (PLD), to obtain oxides thin films with particular properties. Our goal was to verify the quality of pure and Ca-doped $\mathrm{CoO}$ thin films in order to find optimal conditions for their preparation using PLD technique.

\section{Experimental procedure}

Pulsed Laser Deposition (PLD) process was performed using LOTIS Tii Nd:YAG; Model LS-2147 pulsed laser (wavelength of $266 \mathrm{~nm}$, pump energy $40 \mathrm{~J}$ and laser fluency in the range $3.89-5.48 \mathrm{~J} / \mathrm{cm}^{2}$ ). During ablation process a frequency of $10 \mathrm{~Hz}$ and a dwell time of the laser pulse of 18 ns were applied. The laser deposition was performed in a vacuum chamber equipped with a rotating target support and a substrate holder, with no heating applied. At first the chamber was kept under dynamic vacuum $5 \times 10^{-6}$ mbar and next the oxygen atmosphere was used for deposition process $\left(p_{\mathrm{O}_{2}}=5 \times 10^{-2} \mathrm{mbar}\right)$. For all deposition experiments Si single crystals (room temperature) were used as substrates. Time of each film deposition was set to $1 \mathrm{~h}$.

The ablation targets were pure $\mathrm{CoO}$ or $\mathrm{CoO}$ and $\mathrm{CaO}$ oxides mixtures with specific composition ratio: $\mathrm{CoO}+$ 1 wt. $\%$ of $\mathrm{Ca}, \mathrm{CoO}+3.5$ wt. $\%$ of $\mathrm{Ca}$, and $\mathrm{CoO}+6$ wt. $\%$ of Ca. Samples were cold pressed under the pressure of $400 \mathrm{MPa}$ with a little addition of polyvinyl alcohol $(6 \%$ water solution) and annealed in $\mathrm{Ar}$ at the temperature from the range of $100-1100^{\circ} \mathrm{C}$. The quality and chemical composition of obtained targets (Fig. 1) was precisely checked. 


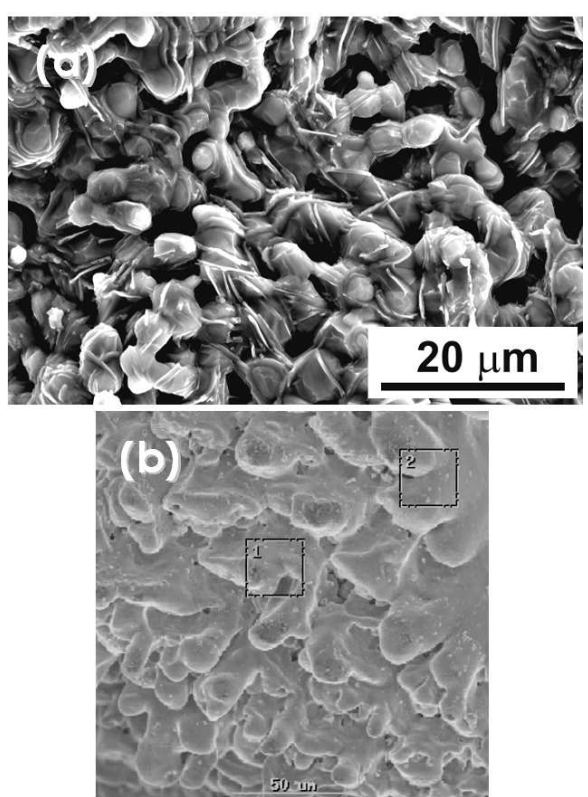

Fig. 1. SEM microstructure of (Co, Ca)O target (a) before and (b) after laser ablation process, with EDS analysis areas.

For characterisation of obtained surface thin films the Scanning Electron Microscopy (HITACHI S-3500N Scanning Electron Microscope), Atomic Force Microscopy (Atomic Force Microscope v 5.01 - built in Institute of Nuclear Physics Polish Academy of Science, KrakowMuenster), X-ray Diffraction (XRD apparatus model HZG-4) and X-ray Photoelectron Spectroscopy (XPS apparatus Vacuum Scientific Workshop Ltd. England with Galileo electron analyser) investigations have been used to reveal the microstructural details. In addition, Energy-Dispersive X-ray Spectroscopy (EDS) has been applied for chemical microanalysis of the deposited films. Nanohardness measurements and scratch-test have been performed to define the quality and adhesion of oxide films.

\section{Results and discussion}

Using described deposition conditions all of produced thin films (pure $\mathrm{CoO}$ and ( $\mathrm{Co}, \mathrm{Ca}) \mathrm{O}$ oxides) were thin, about $50 \mathrm{~nm}$, with no cracks and porosity observed on their surface (Fig. 2). Some droplets are present on the surface of thin films but their amount is limited. The Ca concentration increases their number.

Energy-dispersive X-ray spectroscopy (EDS) studies show, that the surface films deposited on the Si substrate at room temperature are composed generally of $\mathrm{CoO}$ and $\mathrm{CaO}$ (Fig. 3). Droplets observed on the deposited surfaces are generally calcium rich. The dopant concentration is a little higher than for surface film that can be compared in the Table I. For the highest Ca concentration the amount of dopant is over $50 \%$ higher in droplets than in the deposited film.

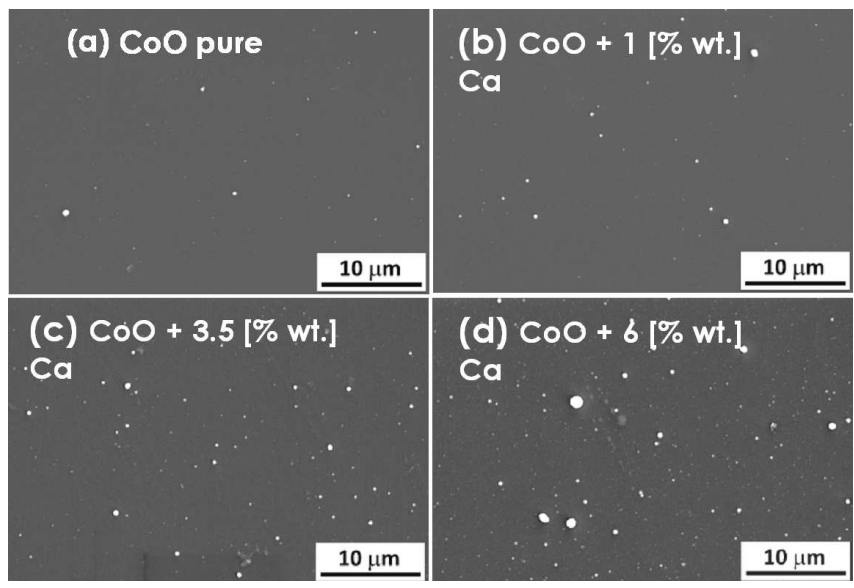

Fig. 2. SEM image of (a) $\mathrm{CoO}$ and (b-d) (Co, Ca)O thin layers surface with different $\mathrm{Ca}$ concentration: (b) 1 wt.\% of $\mathrm{Ca}$, (c) 3.5 wt.\% of $\mathrm{Ca}$ and (d) 6 wt.\% of Ca.
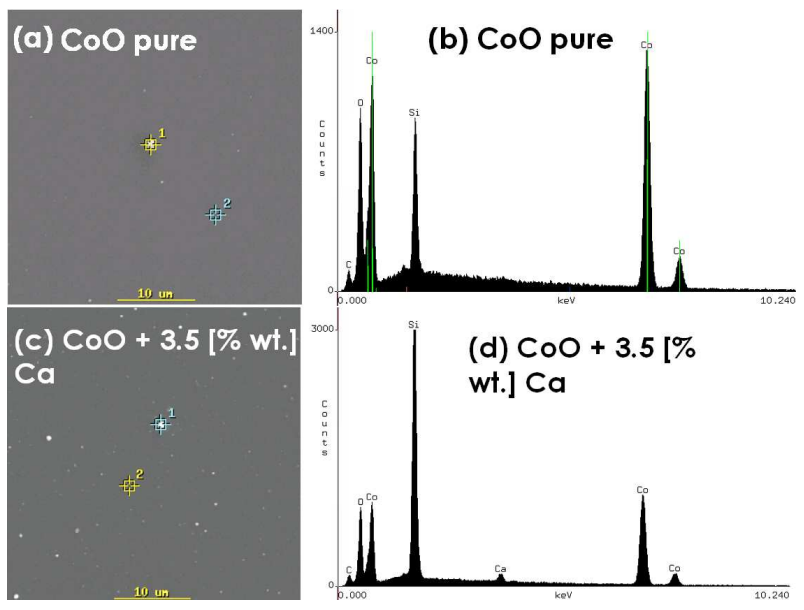

Fig. 3. $\mathrm{CoO}$ (a) and ( $\mathrm{Co}, \mathrm{Ca}) \mathrm{O}$ (c) thin layers with EDS analysis points and analysis results (b) for $\mathrm{CoO}$ pure and (d) $\mathrm{CoO}+1$ wt.\% of Ca respectively.

The results of Atomic Force Microscopy (AFM) investigation indicate that the surface thin films of $\mathrm{CoO}$ deposited on silicon substrate at room temperature are quite smooth (Fig. 4a). The separate trapezium in cross-section columns (about $130 \mathrm{~nm}$ in height) were observed. However the surface layers of Ca-doped $\mathrm{CoO}$ deposited on silicon substrate reveal the topography built from set of columns with the same shape, smooth on the top (Fig. 4b,c). This allows to conclude that during deposition process the column crystal growth takes place on the Si substrate.

In order to study the phase composition of obtained thin films the X-ray Diffraction (XRD) analysis has been made. Figure 5 shows X-ray diffraction diagrams of pure and $\mathrm{Ca}$-doped $\mathrm{CoO}$ surface thin films deposited at room temperature. The diagram confirms the presence of $\mathrm{CoO}$ and $\mathrm{Co}_{3} \mathrm{O}_{4}$ in all of samples, however it can be noticed 
that with the $\mathrm{Ca}$ concentration increase $\mathrm{CaO}$ phase appears (for $3.5 \mathrm{wt} . \%$ of $\mathrm{Ca}$ ). For highest Ca concentration $(6$ wt. $\% \mathrm{Ca}), \mathrm{CaO}$ phase disappears and strong peak from complex calcium cobaltite $\mathrm{Ca}_{3} \mathrm{Co}_{4} \mathrm{O}_{9}$ is revealed. Pres- ence of $\mathrm{SiO}_{2}$ phase (between the substrate and the deposited thin film) can be explained as a result of very fast Si oxidation during deposition process.

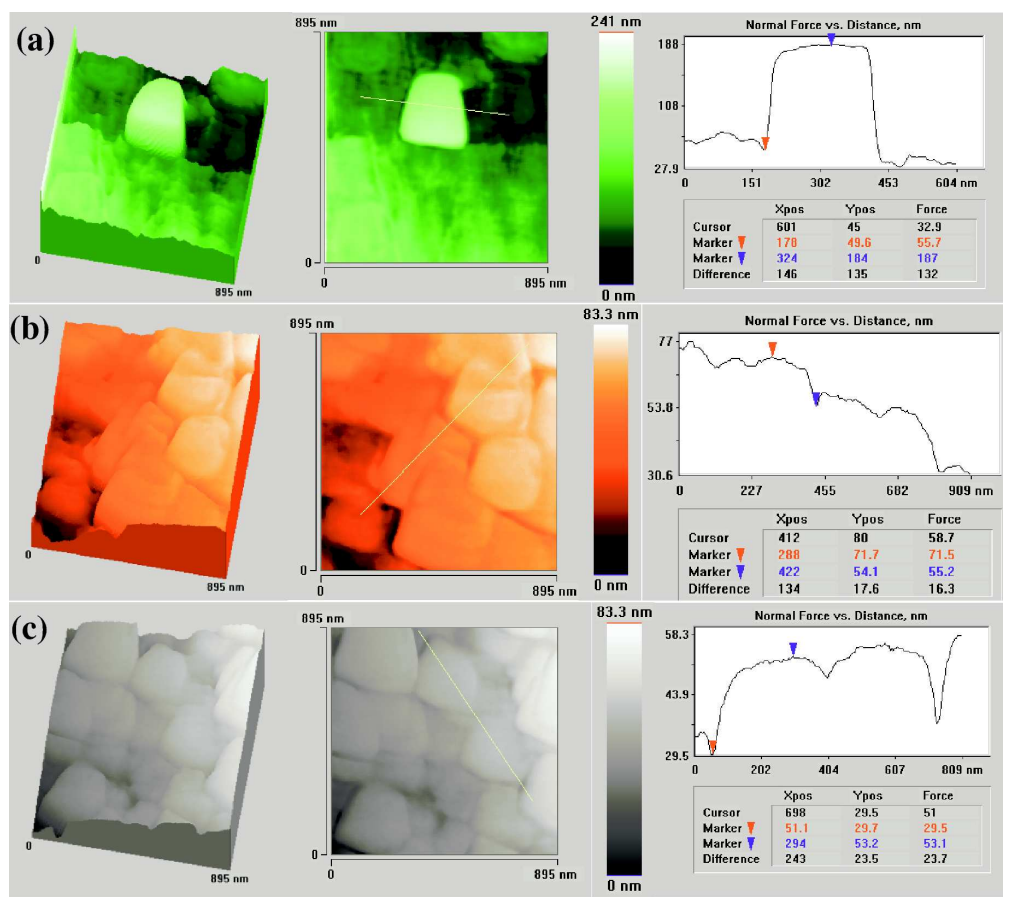

Fig. 4. Image of surface layer topography and vertical section profile with measurements (a) CoO pure, (b) $\mathrm{CoO}+1$ wt. $\%$ of $\mathrm{Ca}$ and (c) $\mathrm{CoO}+6$ wt.\% of Ca.

The surface composition was studied using an XPS method instrument equipped with a concentric hemispherical of diameter of $150 \mathrm{~mm}$ electron analyser and a two-plate 18-channel detector. The electron analyser was operated in fixed-analyse transmission (FAT) with a constant pass energy of $22.5 \mathrm{eV}$. As an X-ray source the $\mathrm{Mg}$ anode with the $\mathrm{K} \alpha(1253.6 \mathrm{eV})$ radiation of $208 \mathrm{~W}$ was applied. The background pressure during the experiments was better than $1 \times 10^{-8}$ mbar. Calibration of the binding energy scale was done by assuming the position of the $\mathrm{C}$ 1s line of $\mathrm{C}-\mathrm{C}$ and $\mathrm{C}-\mathrm{H}$ bonding at $284.6 \mathrm{eV}$. Quantitative analysis has been made for Co and Ca (Table II). The increased $\mathrm{Ca}$ concentration observed for all samples may be related to the surface segregation of dopant during epitaxial column growth of deposited films. Figure 6 shows results of XPS analysis made for sample of $\mathrm{CoO}$ $+1 \mathrm{wt} . \%$ Ca. For all of analysed samples the Co $2 p$ and Ca $2 p$ peaks positions are characteristic for the oxidation state +2 , however for cobalt analysis $\mathrm{Co}_{3} \mathrm{O}_{4}$ phase presence is highly possible (peaks locations are very similar).

In order to verify the quality of obtained thin films nanohardness (Vickers technique nanohardness and nano-scratch tester, CSM Instruments SA) measurements has been performed. The load force $7 \mathrm{mN}$ has been applied during $10 \mathrm{~s}$. It can be seen in Fig. 7 that the hard-
TABLE I

The average concentrations of elements in selected few EDS analysis points for deposited film and droplets.

\begin{tabular}{c|c|c|c|c|c}
\hline \hline \multirow{2}{*}{ Sample } & \multirow{2}{*}{ Element } & \multicolumn{2}{|c|}{ Deposited film } & \multicolumn{2}{|c}{ Droplets } \\
\cline { 3 - 6 } & $\begin{array}{c}\text { Element } \\
{[w t . \%]}\end{array}$ & $\begin{array}{c}\text { Err. } \\
{[\text { wt.\%] }}\end{array}$ & $\begin{array}{c}\text { Element } \\
{[w t . \%]}\end{array}$ & $\begin{array}{c}\text { Err. } \\
{[\text { wt.\%] }}\end{array}$ \\
\hline \multirow{2}{*}{$\mathrm{CoO}$ pure } & $\mathrm{Co}-\mathrm{K}$ & 100.00 & \pm 7.4 & 99.83 & \pm 2.3 \\
& $\mathrm{Ca}-\mathrm{K}$ & 0.00 & \pm 0.0 & 0.17 & \pm 0.1 \\
\hline \multirow{2}{*}{$\mathrm{CoO}+1$ wt.\% of $\mathrm{Ca}$} & $\mathrm{Co}-\mathrm{K}$ & 98.85 & \pm 3.2 & 98.05 & \pm 2.7 \\
& $\mathrm{Ca}-\mathrm{K}$ & 1.15 & \pm 0.2 & 1.95 & \pm 0.4 \\
\hline \multirow{2}{*}{$\mathrm{CoO}+3.5$ wt.\% of $\mathrm{Ca}$} & $\mathrm{Co}-\mathrm{K}$ & 96.43 & \pm 2.5 & 93.17 & \pm 3.6 \\
& $\mathrm{Ca}-\mathrm{K}$ & 3.57 & \pm 0.3 & 6.83 & \pm 0.4 \\
\hline \multirow{2}{*}{$\mathrm{CoO}+6$ wt.\% of $\mathrm{Ca}$} & $\mathrm{Co}-\mathrm{K}$ & 93.92 & \pm 2.9 & 89.17 & \pm 2.9 \\
& $\mathrm{Ca}-\mathrm{K}$ & 6.08 & \pm 0.2 & 10.83 & \pm 0.6
\end{tabular}

ness of pure $\mathrm{CoO}$ is lower than for $\mathrm{Si}$ substrate $(7.94 \mathrm{GPa}$ and $9.87 \mathrm{GPa}$ respectively) but with $\mathrm{Ca}$ content it increase to the value of $11.27 \mathrm{GPa}$. For highest Ca concentration one can notice the decrease of nanohardness value $(6.44 \mathrm{GPa})$ which is the result of calcium cobaltite phase presence $\left(\mathrm{Ca}_{3} \mathrm{Co}_{4} \mathrm{O}_{9}\right)$.

Measurements of surface films adhesion have been made during scratch-tests. For these experiments of linear scratch the following conditions were applied: ini- 


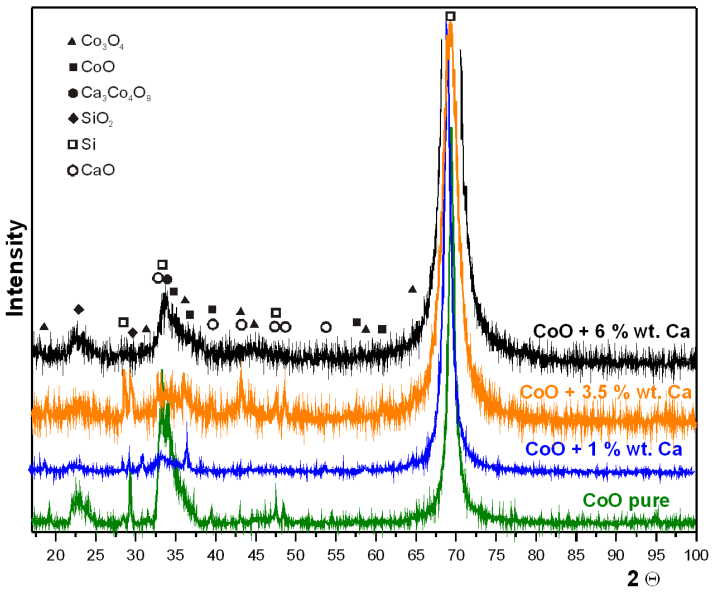

Fig. 5. Diffraction patterns from pure and Ca-doped $\mathrm{CoO}$ thin films deposited on Si surface at room temperature.

\section{TABLE II}

Results of Ca quantitative analysis in $(\mathrm{Co}, \mathrm{Ca}) \mathrm{O}$ surface layers using XPS technique.

\begin{tabular}{l|c}
\hline \hline \multicolumn{1}{c|}{ Sample } & Ca [wt.\%] \\
\hline $\mathrm{CoO}+1$ wt. $\%$ of $\mathrm{Ca}$ & 4.1 \\
$\mathrm{CoO}+3.5$ wt. $\%$ of $\mathrm{Ca}$ & 11.7 \\
$\mathrm{CoO}+6$ wt. $\%$ of $\mathrm{Ca}$ & 10.7
\end{tabular}

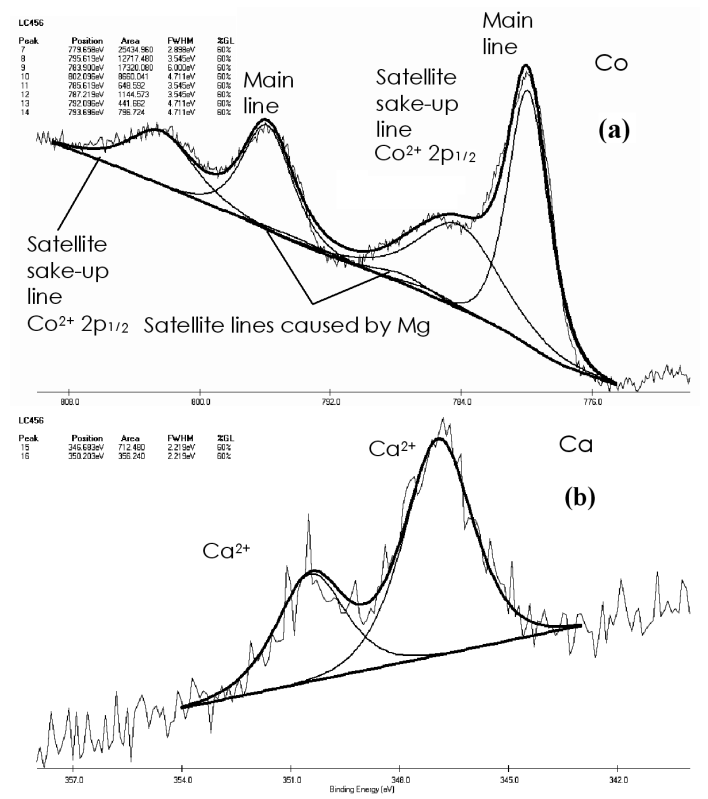

Fig. 6. XPS peaks positions characteristic for oxide state +2 , (a) for Co $2 p$, and (b) for Ca $2 p$, obtained for $\mathrm{CoO}+1$ wt. $\%$ of Ca sample.

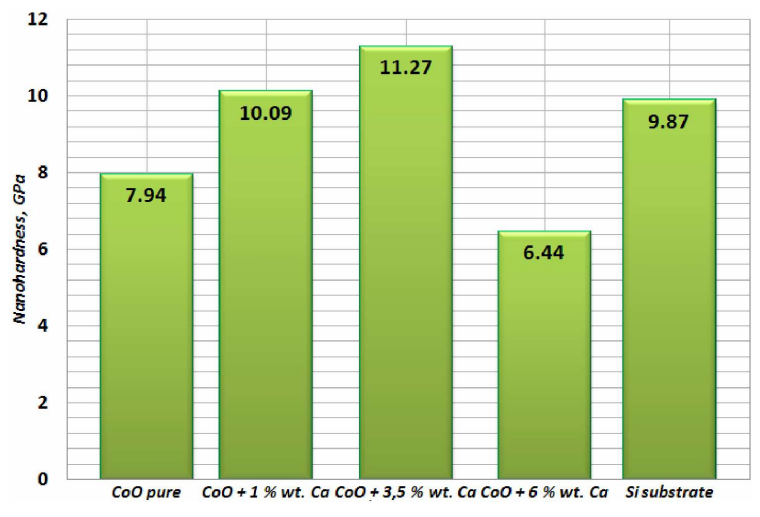

Fig. 7. Results of nanohardness measurements for pure and Ca-doped $\mathrm{CoO}$, as well as for $\mathrm{Si}$ substrate.

TABLE III

Results of regular force measurements during pure and $\mathrm{Ca}$-doped $\mathrm{CoO}$ thin films scratch tests.

\begin{tabular}{l|c|c}
\hline \hline \multirow{2}{*}{ Sample } & \multicolumn{2}{|c}{ Critical load [mN] } \\
\cline { 2 - 3 } & Initial fracture & Delamination \\
\hline $\mathrm{CoO}$ pure & 9.60 & 10.49 \\
$\mathrm{CoO}+1$ wt. $\%$ of $\mathrm{Ca}$ & 7.82 & 8.78 \\
$\mathrm{CoO}+3.5$ wt. $\%$ of $\mathrm{Ca}$ & 8.41 & 9.15 \\
$\mathrm{CoO}+6$ wt. $\%$ of $\mathrm{Ca}$ & 11.96 & 13.32
\end{tabular}

tial load $-4 \mathrm{mN}$, final load $-20 \mathrm{mN}$, loading/unloading rate $-100 \mathrm{mN} / \mathrm{min}$, scratch length $-1 \mathrm{~mm}$ and scratch speed $-6.25 \mathrm{~mm} / \mathrm{min}$. The values of specific critical loads were estimated for appearance of initial fractures and for complete delamination of deposited films (Table III). In this case the presence of Ca content has the positive influence on the thin films adhesion, with the increase of calcium concentration the greater force is needed to destroy the deposited film.

\section{Conclusions}

According to results of structure and properties investigations made for pure and Ca-doped thin films (deposited by PLD technique) the following conclusions can be proposed:

1. It is possible to carry the chemical composition of pure and Ca-doped $\mathrm{CoO}$ from targets to Si substrate at room temperature by Pulsed Laser Deposition technique.

2. Obtained thin films are good quality with no visible defects on the surface (cracks or porosity) and little number of $\mathrm{Ca}$ rich droplets. For the higher calcium concentration the $\mathrm{Ca}_{3} \mathrm{Co}_{4} \mathrm{O}_{9}$ phase appears (apart from $\mathrm{CoO}$ and $\mathrm{Co}_{3} \mathrm{O}_{4}$ observed for all samples). 
3. The results of Atomic Force Microscopy (AFM) investigation indicate that during deposition process the trapezium in cross-section column crystal growth takes place on the Si substrate.

4. The XPS analysis results show that the concentration of $\mathrm{Ca}$ is higher at the surface of deposited films which is a result of $\mathrm{Ca}$ surface segregation during epitaxial column growth.

5. The hardness of obtained films depends on the Ca concentration which corresponds to phase formation during deposition. For 6 wt.\% of $\mathrm{Ca}$ the $\mathrm{Ca}_{3} \mathrm{Co}_{4} \mathrm{O}_{9}$ phase appears and the value of nanohardness decrease.

6. Adhesion of deposited ( $\mathrm{Co}, \mathrm{Ca}) \mathrm{O}$ films increases with the $\mathrm{Ca}$ concentration.

\section{Acknowledgments}

This work is supported by Polish Ministry of Science and Higher Education, grant no. N N507 407236.

\section{References}

[1] J. Kusiński, E. Cieniek, G. Petot-Ervas, C. Petot, G. Baldinozzi, Journal of Microscopy 224, 30 (2006).

[2] Ł. Cieniek, J. Kusiński, G. Baldinozzi, Inżynieria Materiatowa 157, 242 (2007).

[3] N. Bahlawane, Appl. Catal. B 67, 168 (2006).

[4] P.S. Patil, L.D. Kadam, C.D. Lokhande, Sol. Energy Mater. Sol. Cells 53, 229 (1998).

[5] J.B. Wu, J.P. Tu, X.L. Wang, W.K. Zhang, Int. Journal of Hydrogen Energy 32, 5 (2007).

[6] C. Cantalini, M. Post, D. Buso, M. Guglielmi, A. Martucci, Sens. Actuators B 108, 184 (2005).

[7] W. Wang, G. Zhang, J. Cryst. Growth 311, 4275 (2009). 